\title{
Insulinoma in postprandial hypoglycaemia and aggressive behaviour
}

\author{
Shwe Zin Chit Pan 1,2, Singhan Krishnan', Anitha Mathews ${ }^{1}$ \\ 'Department of Diabetes and Endocrinology, Hinchingbrooke Health Care NHS Trust, Huntingdon, Cambridgeshire, UK \\ ${ }^{2}$ Queen Mary, University of London
}

\section{Background:}

Fasting hypoglycaemia is a common presenting symptom of insulinoma. However, insulinoma should be considered as a potential cause in those presenting with symptoms of hypoglycaemia after meal.(1-3) Here we report a case who initially presented with postprandial symptoms though there was evidence of fasting hypoglycaemia subsequently.

\section{Clinical presentation:}

A 57-year-old lady initially presented with a 2 year history of palpitation, feeling hot, sweating and dizzy episodes which occurred within 2 hours of meals. She also gained some weight. There was no history of nocturnal or fasting hypoglycaemia. Past medical history included CREST syndrome. There was no family history of note On examination she has a BMI of 34.5.

\section{Investigations:}

Thyroid function tests, plasma metanephrines, short synacthen test, urea and electrolytes, renal and liver function tests were normal. Further monitoring of capillary glucose revealed fasting hypoglycaemia.

Subsequently, a supervised 48-hour fast test was performed. Patient developed hypoglycaemia within first 12 hours. The lowest blood glucose level was $2.2 \mathrm{mmol} / \mathrm{l}$. There were elevated insulin level $49 \mathrm{pmol} / \mathrm{l}$ and pro-insulin level $22.2 \mathrm{pmol} / \mathrm{l}$. C peptide level was 863 pmol/l. Sulphonylurea screen was negative. Hypoglycemia was associated with neuroglycopenic symptoms particularly very aggressive behaviour.

CT scan of the abdomen and EUS -endoscopic ultrasound have confirmed $1.2 \mathrm{~mm}$ solitary insulinoma in the tail of pancreas.

\section{Management:}

Surgery was performed subsequently and the histology confirmed insulinoma.

Conclusion: This case has highlighted the importance of awareness of post prandial hypogycemic symptoms as presenting feature of insulinoma.

\section{References:}

1. Placzkowski KA, Vella A, Thompson GB, Grant CS, Reading CC, Charboneau JW, et al. Secular trends in the presentation and management of functioning insulinoma at the Mayo Clinic, 1987-2007. J Clin Endocrinol Metab. 2009 Apr;94(4):1069-73.

2. Madathil A, Weaver J. Insulinoma presenting as postprandial hypoglycaemia. BMJ Case Rep. 2011;2011.

3. Connor $\mathrm{H}$, Scarpello $\mathrm{JH}$. An insulinoma presenting with reactive hypoglycaemia. Postgrad Med J. 1979 Oct;55(648):735-8.

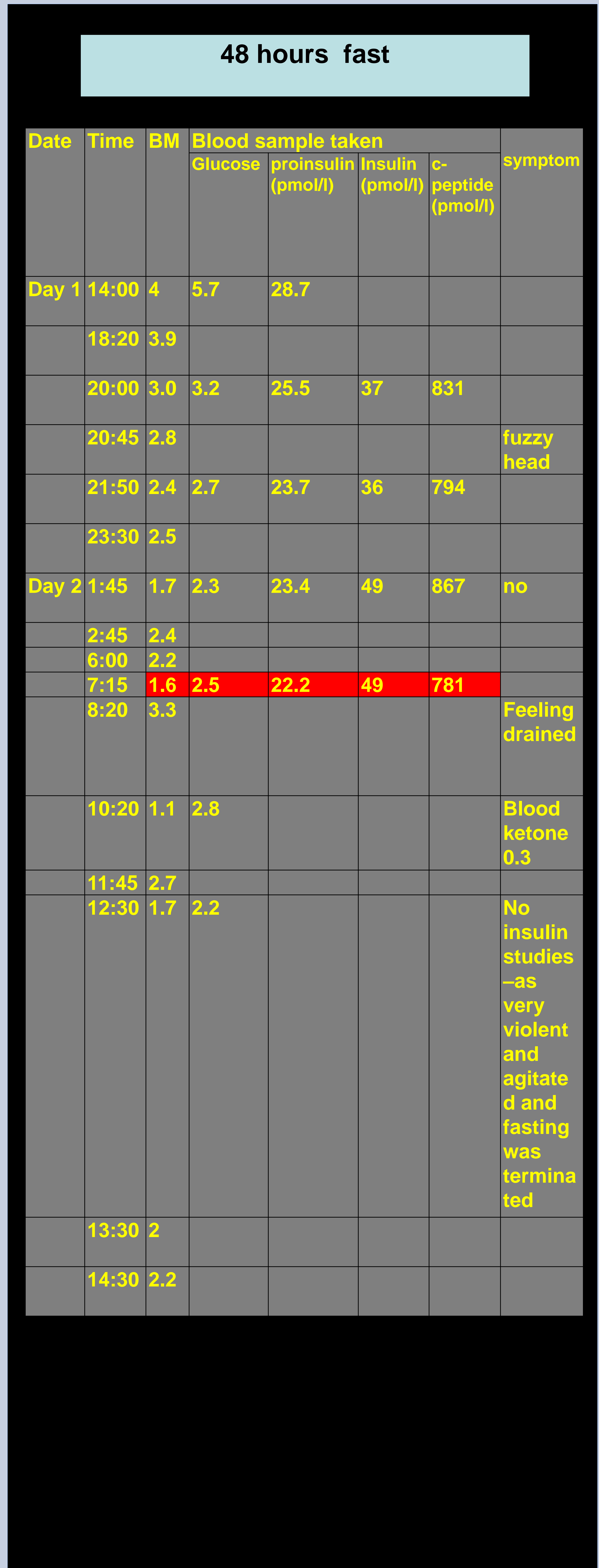

